\title{
Effect of the chemical structure of alkyl acrylates on their defoaming activity in crude oil: experimental and theoretical studies
}

Authors: Enrique Cevada, ${ }^{\mathrm{a}, \mathrm{b}}$ Jessica V. Fuentes, ${ }^{\mathrm{a}}$ Edgar Benedicto Zamora, ${ }^{\mathrm{a}}$ Edgar Ivan Hernandez, ${ }^{\mathrm{a}}$

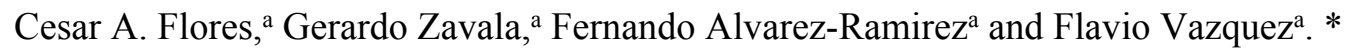

a Instituto Mexicano del Petróleo, Eje Central Lázaro Cárdenas No. 152, San Bartolo Atepehuacan, Delegación Gustavo A. Madero, Ciudad de México, C.P. 07730, México. ${ }^{b}$ Escuela Superior de Ingeniería Química e Industrias Extractivas, Instituto Politécnico Nacional, Unidad Adolfo López Mateos, Zacatenco, Ciudad de México, México.

Supplementary Information

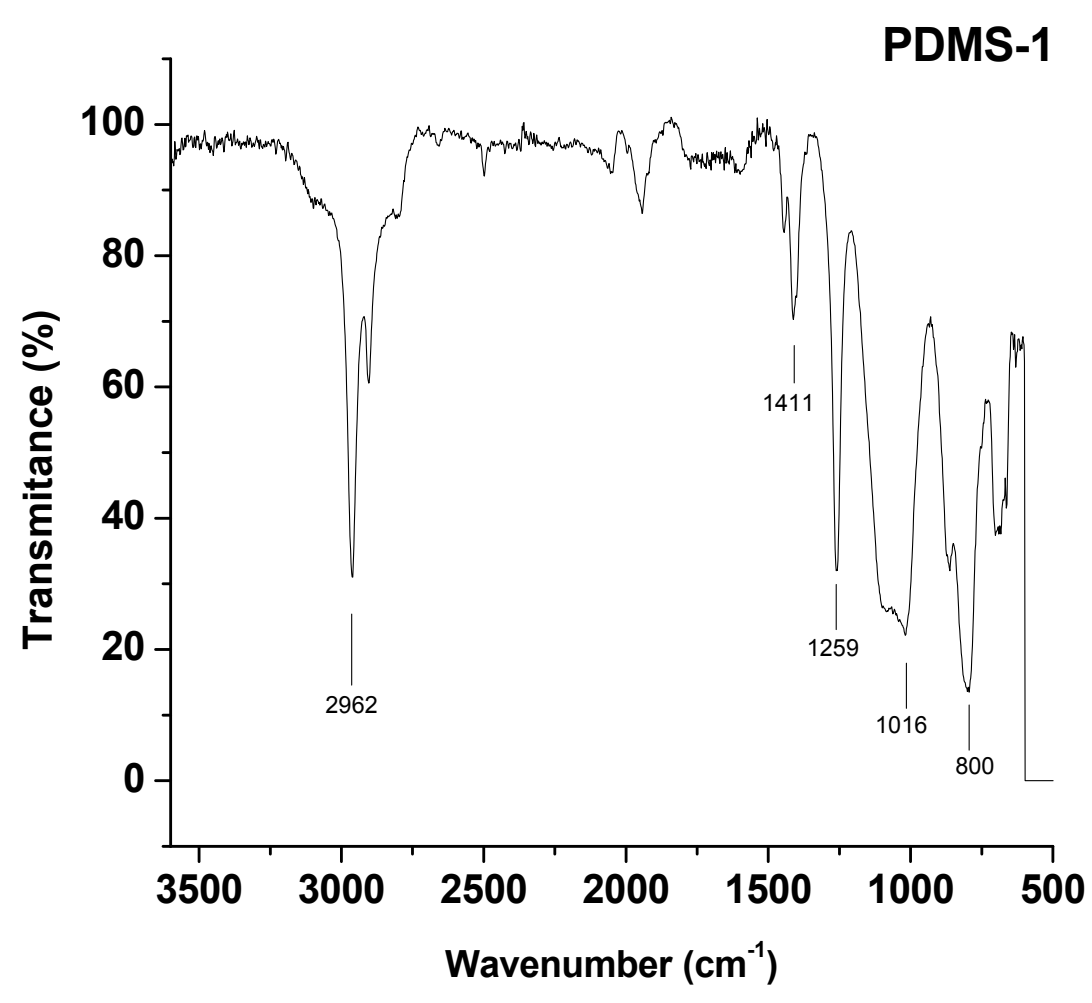

Fig. S1. FTIR spectrum of the PDMS commercial antifoaming agent. 


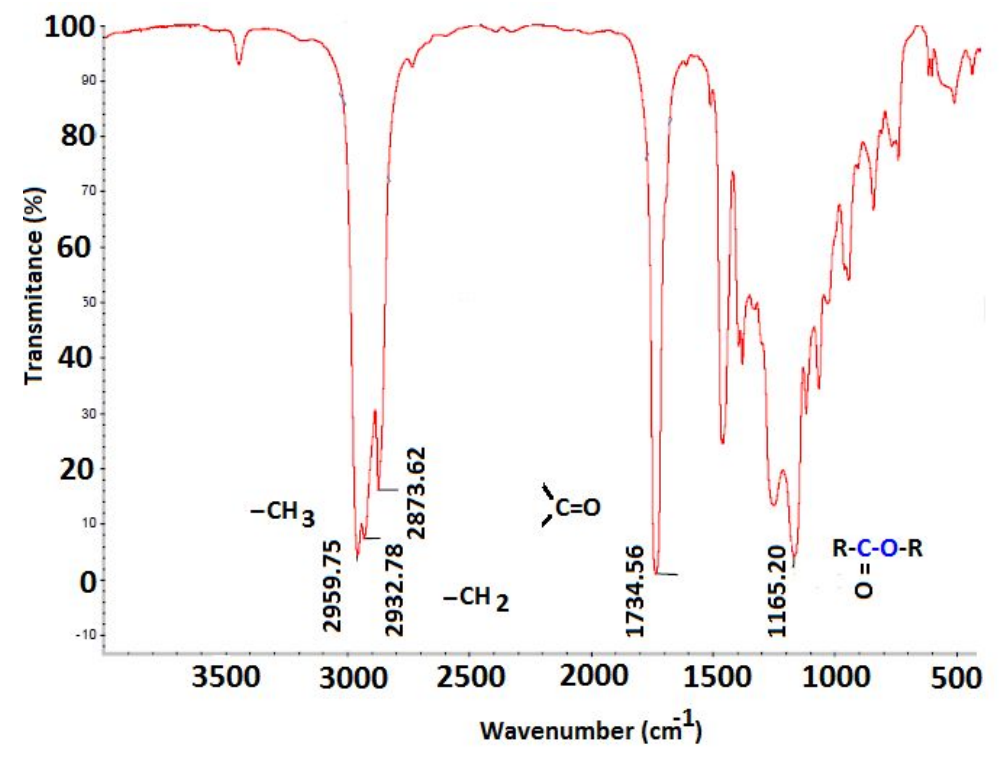

Fig. S2. FTIR spectrum corresponding to homopolymer of 2-ethylhexyl acrylate (PEHA-1). 


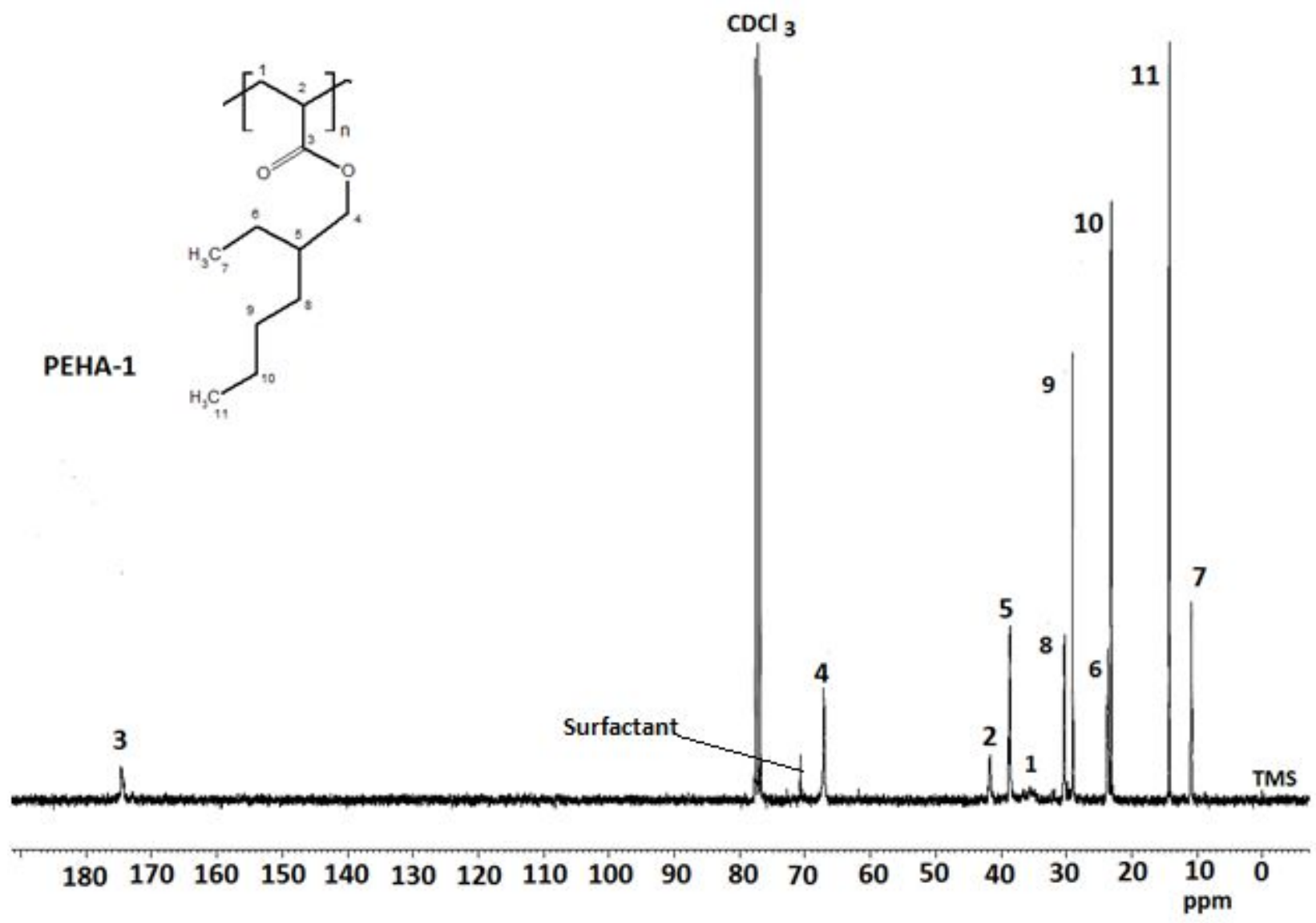

Fig. S3. ${ }^{13} \mathrm{C}$ NMR spectrum of the PEHA-1 homopolymer $\left(\bar{M}_{w}=12724 \mathrm{~g} \mathrm{~mol}^{-1}, P I=2.3\right)$ in $\mathrm{CDCl}_{3}$ 


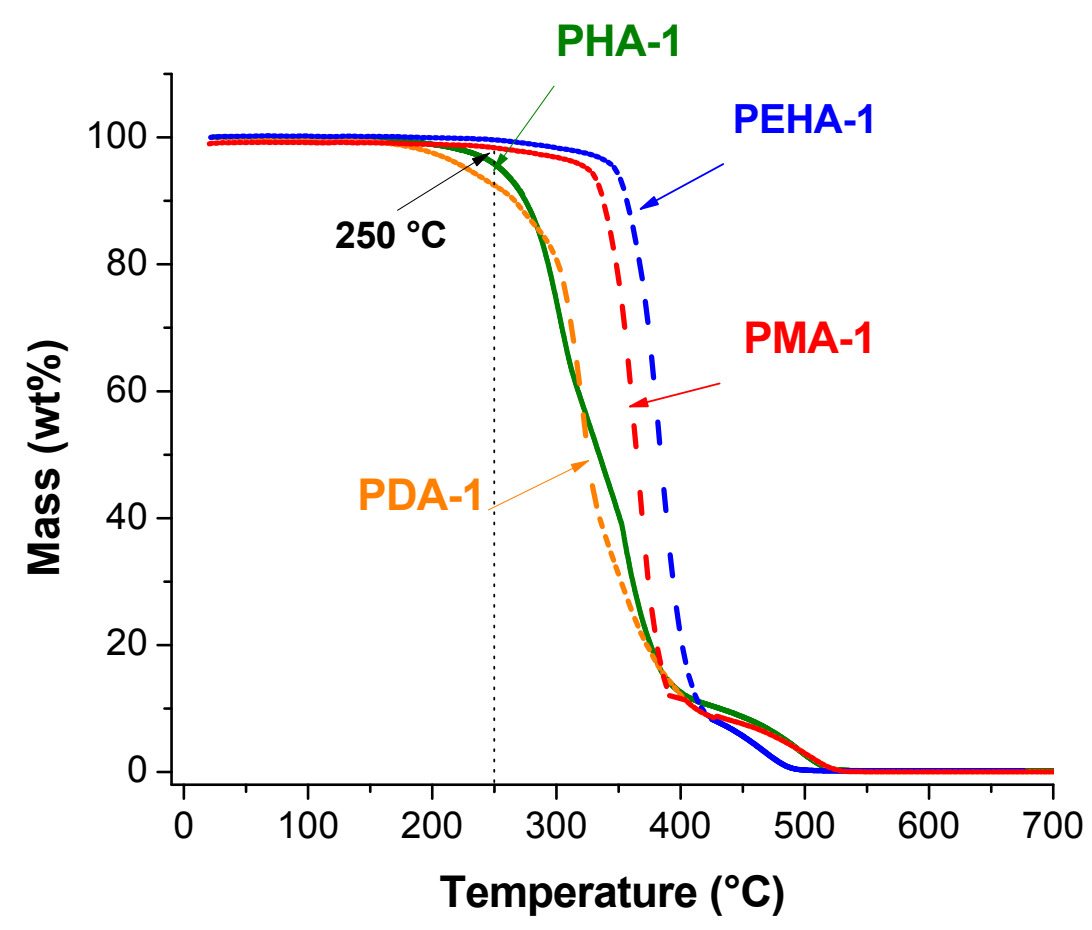

Fig. S4. Thermal analysis of acrylic homopolymers: PMA-1 $\left(\mathrm{M}_{\mathrm{w}}=10300 \mathrm{~g} / \mathrm{mol}, \mathrm{PI}=1.7\right)$; PHA-1 $\left(\mathrm{M}_{\mathrm{w}}=12848 \mathrm{~g} / \mathrm{mol}, \mathrm{PI}=2.0\right)$; PEHA-1 $\left(\mathrm{M}_{\mathrm{w}}=12724 \mathrm{~g} / \mathrm{mol}, \mathrm{PI}=2.3\right)$; PDA-1 $\left(\mathrm{M}_{\mathrm{w}}\right.$ $=8567 \mathrm{~g} / \mathrm{mol}, \mathrm{PI}=2.1) ;$ from room temperature to $700^{\circ} \mathrm{C}$, at a heating rate of $\dot{q}=10^{\circ} \mathrm{C} / \mathrm{min}$, under air atmosphere. 

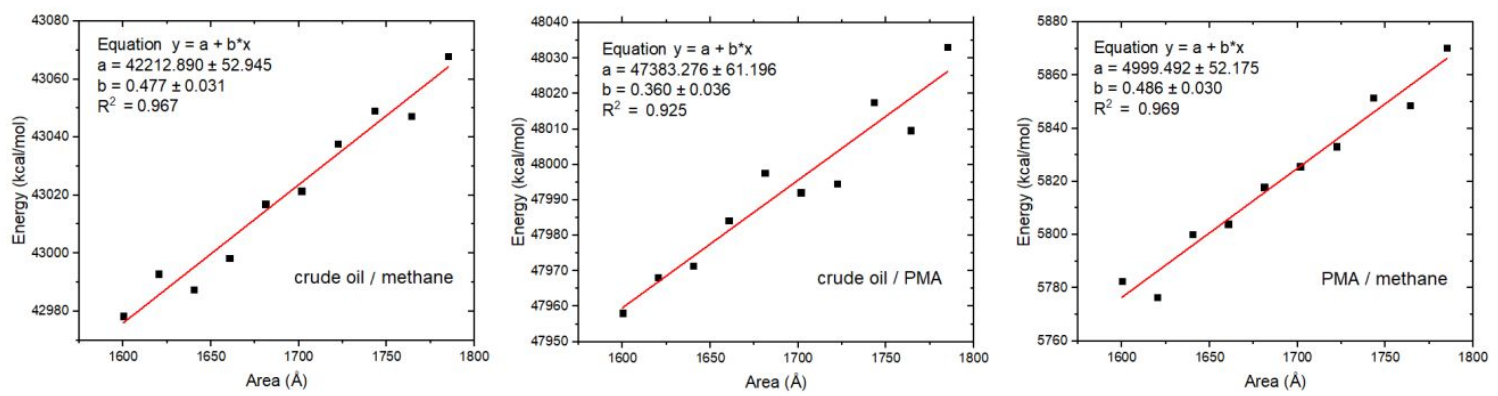

Fig. S5. Linear adjustment of the variation of energy as a function of the interfacial area for the case of Poly(methyl acrylate), $86.09 \mathrm{~g} / \mathrm{mol}, 60$ PMA Units. The slope of these adjustments is proportional to the interfacial tension between the species.
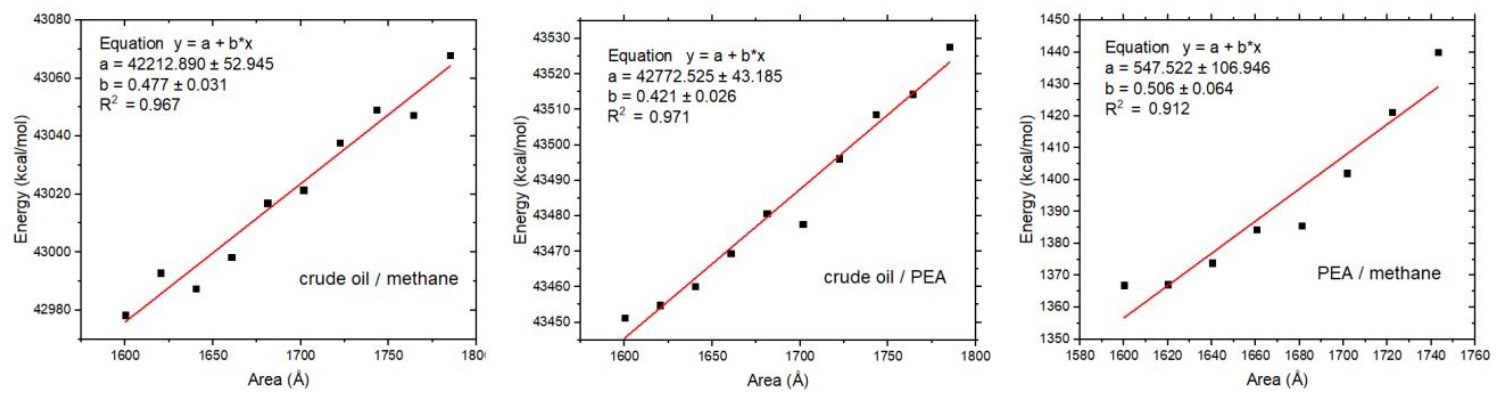

Fig. S6. Linear adjustment of the variation of energy as a function of the interfacial area for the case of Poly(ethyl acrylate), $100.117 \mathrm{~g} / \mathrm{mol}, 60$ PEA units. The slope of these adjustments is proportional to the interfacial tension between the species. 

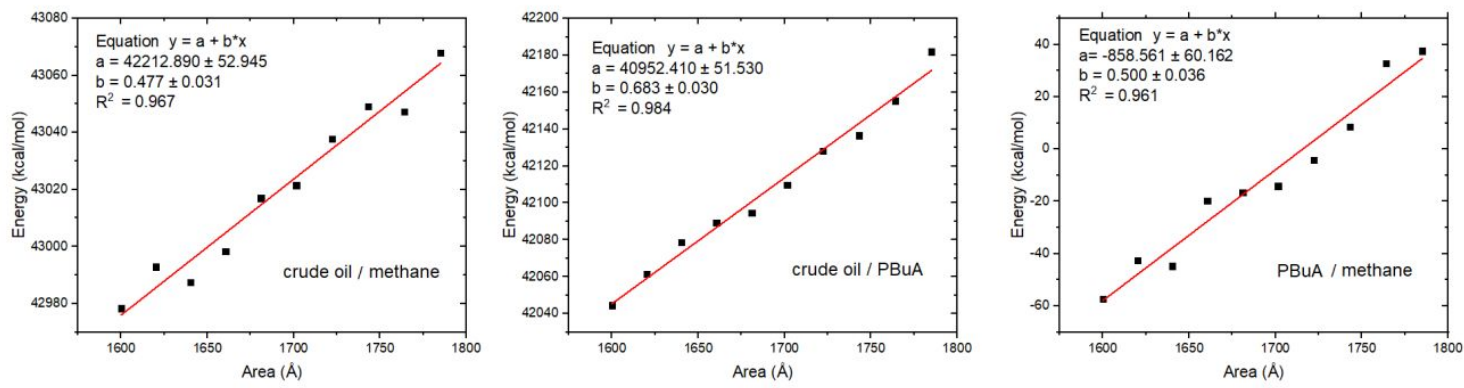

Fig. S7. Linear adjustment of the variation of energy as a function of the interfacial area of Poly(butyl acrylate), $128.171 \mathrm{~g} / \mathrm{mol}, 60 \mathrm{PBuA}$ units. The slope of these adjustments is proportional to the interfacial tension between the species.
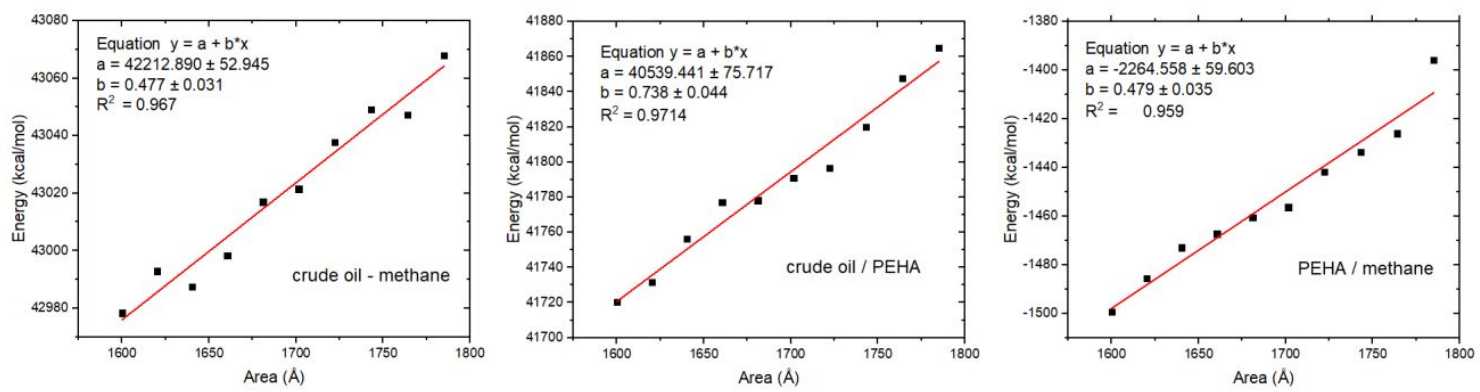

Fig. S8. Linear adjustment of the variation of energy as a function of the interfacial area for the case of for the case of Poly(2-ethylhexyl acrylate), $184.279 \mathrm{~g} / \mathrm{mol}, 60$ PEHA units. The slope of these adjustments is proportional to the interfacial tension between the species. 

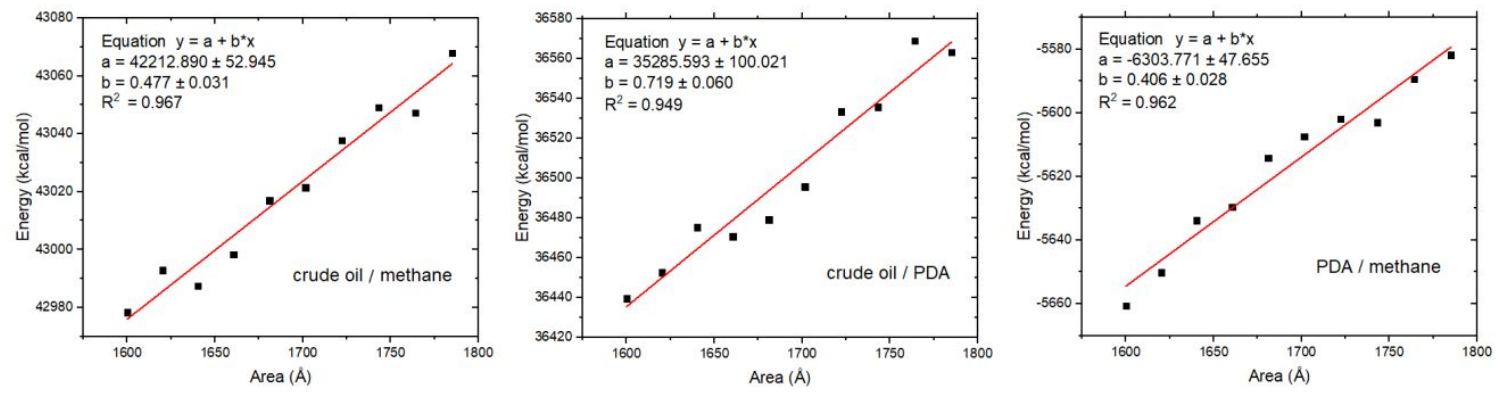

Fig. S9. Linear adjustment of the variation of energy as a function of the interfacial area for the case of Poly(dodecyl acrylate) $240.387 \mathrm{~g} / \mathrm{mol}$, 60 PDA units . The slope of these adjustments is proportional to the interfacial tension between the species. 